\title{
Factors predicting adverse events associated with pregabalin administered for neuropathic pain relief
}

\author{
Yuko Kanbayashi PhD ${ }^{1,2}$, Keiko Onishi MD²,3,4, Toyoshi Hosokawa MD PhD2,3,4
}

\begin{abstract}
Y Kanbayashi, K Onishi, T Hosokawa. Factors predicting adverse events associated with pregabalin administered for neuropathic pain relief. Pain Res Manag 2014;19(6):e164-e167.
\end{abstract}

BACKGROUND: Pregabalin administration is occasionally abandoned due to adverse events such as somnolence, dizziness, unsteadiness, weight gain and edema. However, the exact causes of these differences in adverse events associated with pregabalin have not been elucidated.

OBJECTIVE: To identify factors predicting adverse events associated with pregabalin administered for neuropathic pain.

METHODS: The present study was a retrospective analysis involving 208 patients with neuropathic pain who had been treated with pregabalin in the pain clinic at the authors' hospital between July 2010 and September 2011. Variables were extracted from the clinical records for regression analysis of factors related to the occurrence of adverse events associated with pregabalin administration. Multivariate logistic regression analysis was used to examine the relationship between various predictive factors and the adverse events.

RESULTS: Predictive factors were: duration of therapy (OR 1.684 [95\% CI 1.179 to 2.406]; $\mathrm{P}=0.0042$ ) for somnolence; nonsteroidal anti-inflammatory drugs (OR 0.132 [95\% Cl 0.030 to 0.578]; $\mathrm{P}=0.0072$ ), age (OR 3.137 [95\% CI 1.220 to 8.066 ]; $\mathrm{P}=0.0177$ ) and maintenance dose (OR 0.437 [95\% CI 0.217 to 0.880 ]; $\mathrm{P}=0.0205$ ) for unsteadiness; serum creatinine (OR 6.439 [95\% CI 1.541 to 26.902]; $\mathrm{P}=0.0107$ ) for body weight gain; and neurotropin (OR 8.538 [95\% CI 1.159 to 62.901]; $\mathrm{P}=0.0353$ ) and serum creatinine (OR 6.912 [95\% CI 1.118 to 42.726]; $\mathrm{P}=0.0375$ ) for edema. CONCLUSIONS: The results of the present study indicate that care is warranted regarding long durations of therapy for somnolence, advanced age rather than dose-dependent adverse events for unsteadiness, elevated serum creatinine level for weight gain, and elevated serum creatinine level and combination use of neurotropin for edema. The safety of the combined use of pregabalin and nonsteroidal anti-inflammatory drugs were also suggested.

Key Words: Adverse events; Body weight gain; Neuropathic pain; Pregabalin; Somnolence; Unsteadiness

\section{Les facteurs prédictifs d'événements indésirables}

\section{associés à la prégabaline administrée pour soulager la douleur neuropathique}

HISTORIQUE : L'administration de prégabaline est parfois abandonnée
en raison d'événements indésirables comme la somnolence, les étourdisse-
ments, le déséquilibre, la prise de poids et l'œème. Cependant, les causes
exactes des différences en matière d'événements indésirables attribuables à
la prégalabine ne sont pas établies.
OBJECTIF : Déterminer les facteurs indicateurs d'événements indé-
sirables associés à l'administration de prégabaline pour soulager la douleur
neuropathique. neuropathique.

208 patients atteints d'une douleur neuropathique qui avaient été traités à la prégabaline à la clinique de la douleur de l'hôpital des auteurs entre juillet 2010 et septembre 2011. Les chercheurs ont tiré les variables des dossiers cliniques pour effectuer l'analyse de régression des facteurs liés à la survenue d'événements indésirables associés à l'administration de prégabaline. Ils ont utilisé l'analyse de régression logistique multivariée pour examiner le lien entre divers facteurs prédictifs et les événements indésirables.

RÉSULTATS : Les facteurs prédictifs étaient la durée du traitement (RR 1,684 [95 \% IC 1,179 à 2,406]; $\mathrm{P}=0,0042$ ) pour la somnolence, les antiinflammatoires non stéroïdiens ( RR 0,132 [95\% IC 0,030 à 0,578]; $\mathrm{P}=0,0072$ ), l'âge (RR 3,137 [95 \% IC 1,220 à 8,066]; $\mathrm{P}=0,0177$ ) et la dose d'entretien (RR 0,437 [95\% IC 0,217 à 0,880]; $\mathrm{P}=0,0205$ ) pour le déséquilibre, la créatinine sérique (RR 6,439 [95 \% IC 1,541 à 26,902]; $\mathrm{P}=0,0107$ ) pour la prise de poids et la neurotropine (RR 8,538 [95\% IC 1,159 à 62,901]; $\mathrm{P}=0,0353$ ) et la créatinine sérique (RR 6,912 [95 \% IC 1,118 à 42,726]; $\mathrm{P}=0,0375)$ pour l'œdème.

CONCLUSIONS : D'après les résultats de la présente étude, des soins s'imposent pour résorber la somnolence causée par la longue durée du traitement, le déséquilibre est attribuable à l'âge avancé plutôt qu'à un événement indésirable lié à la dose, la prise de poids est secondaire au taux de créatinine sérique élevé et l'œdème est imputable au taux de créatinine élevé associé à l'utilisation de neurotropine. L'innocuité de la prégabaline combinée aux anti-inflammatoires non stéroïdiens a également été invoquée.

\begin{abstract}
Dregabalin, a specific ligand of the alpha-2-delta type 1 and 2 sub1 units of voltage-gated calcium ion channels, is used in the treatment of various types of intractable neuropathic pain (NP) such as postherpetic neuralgia (PHN) (1-9), diabetic peripheral neuropathy (DPNP) (5-13) and cancer-related NP (14). However, pregabalin administration is occasionally abandoned due to adverse events. The most commonly reported adverse events data (all-causality) with pregabalin (regardless of dose) in Japan were dizziness (PHN 31.1\%; DPNP 24.6\%), somnolence (PHN 28.6\%; DPNP 25.7\%), peripheral edema (PHN 12.5\%; DPNP 15.1\%) and weight gain (PHN 11.7\%; DPNP 13.4\%) (15). However, the exact causes of these differences in adverse events of pregabalin have not been elucidated. Therefore, the aim of the present study was to identify predictive factors for adverse events of pregabalin, which will help to establish evidence-based guidelines for the optimal use of pregabalin.
\end{abstract}

\section{METHODS}

Study term and participants

The present study was a retrospective analysis involving 208 patients with NP who had been treated with pregabalin in the pain clinic at the University Hospital at Kyoto Prefectural University of Medicine (Kyoto, Japan) between July 2010 and September 2011. The study protocol was approved by the ethics review boards of Kyoto Prefectural University of Medicine.

\section{Statistical analysis}

Multivariate logistic regression analysis was used to examine the relationships among various predictive factors and adverse events associated with pregabalin administered for the relief of NP. Analyzed adverse events were somnolence, unsteadiness, weight gain and edema. The occurrence of adverse events was recorded by pain clinicians

\section{Departments of ${ }^{1}$ Hospital Pharmacy and ${ }^{2}$ Pain Treatment and Palliative Care Unit, University Hospital; Departments of ${ }^{3}$ Anesthesiology and}

${ }^{4}$ Pain Management and Palliative Care Medicine, Kyoto Prefectural University of Medicine, Graduate School of Medical Science, Kyoto, Japan Correspondence: Dr Yuko Kanbayashi, Department of Hospital Pharmacy, Kyoto Prefectural University of Medicine, Kawaramachi-Hirokoji,

Kamigyo-ku, Kyoto 602-8566, Japan. Telephone 81-75-251-5865, fax 81-75-251-5863, e-mail ykokanba@koto.kpu-m.ac.jp

\section{OPEN ACCESS}

This open-access article is distributed under the terms of the Creative Commons Attribution Non-Commercial License (CC BY-NC) (http:// creativecommons.org/licenses/by-nc/4.0/), which permits reuse, distribution and reproduction of the article, provided that the original work is properly cited and the reuse is restricted to noncommercial purposes. For commercial reuse, contact support@pulsus.com 
TABLE 1

Patient characteristics and extracted factors that may affect effectiveness or adverse effects associated with pregabalin for neuropathic pain $(n=208)$

\begin{tabular}{|c|c|c|}
\hline Characteristic & $\mathrm{n}(\%)^{*}$ & Mean \pm SD (range) \\
\hline Adverse events & $118(56.7)$ & \\
\hline Somnolence & $62(29.8)$ & \\
\hline Dizziness & $6(2.9)$ & \\
\hline Unsteadiness & $49(23.6)$ & \\
\hline $\begin{array}{l}\text { Weight gain, kg, } \\
\text { mean } \pm \text { SD (median) }\end{array}$ & $11(5.3)$ & $4.45 \pm 1.98(4.0)(2.6-9.0)$ \\
\hline Edema & $9(4.3)$ & \\
\hline \multicolumn{3}{|l|}{ Demographic factors } \\
\hline Male sex & $88(42.3)$ & \\
\hline Age, $\geq 60$ years & $145(69.7)$ & $63.3 \pm 15.4(19-91)$ \\
\hline \multicolumn{3}{|l|}{ Physical examination finding } \\
\hline Body mass index & & $22.4 \pm 3.5(15.2-34.5)$ \\
\hline \multicolumn{3}{|c|}{ Dose and duration of pregabalin therapy } \\
\hline $\begin{array}{l}\text { Initial dose, mg/day, } \\
\text { mean } \pm \text { SD (median) }\end{array}$ & $149(71.6)$ & $112.9 \pm 48.8(100)(25-375)$ \\
\hline $\begin{array}{l}\text { Maintenance dose, } \\
\text { mg/day, mean } \pm \text { SD } \\
\text { (median) }\end{array}$ & $111(53.4)$ & $152.2 \pm 96.4(150)(25-450)$ \\
\hline $\begin{array}{l}\text { Duration of therapy } \\
(0 / 1 / 2 / 3)\end{array}$ & $34 / 25 / 31 / 118$ & \\
\hline \multicolumn{3}{|l|}{ Laboratory tests } \\
\hline AST, U/L & & $24.3 \pm 13.6(9-111)$ \\
\hline $\mathrm{ALT}, \mathrm{U} / \mathrm{L}$ & & $20.4 \pm 20.3(4-236)$ \\
\hline \multicolumn{3}{|l|}{ Blood urea nitrogen } \\
\hline $\mathrm{mmol} / \mathrm{L}$ & & $5.7 \pm 2.1(2.0-17.7)$ \\
\hline $\mathrm{mg} / \mathrm{dL}$ & & $16.0 \pm 6.0(5.6-49.5)$ \\
\hline Albumin, g/L & & $40.8 \pm 5.1(16-51)$ \\
\hline \multicolumn{3}{|l|}{ Bilirubin } \\
\hline$\mu \mathrm{mol} / \mathrm{L}$ & & $12.8 \pm 12.0(3.9-157.1)$ \\
\hline $\mathrm{mg} / \mathrm{dL}$ & & $0.75 \pm 0.70(0.23-9.19)$ \\
\hline \multicolumn{3}{|l|}{ Serum creatinine } \\
\hline$\mu \mathrm{mol} / \mathrm{L}$ & $22(10.6)$ & $66.3 \pm 27.4(30.1-231.6)$ \\
\hline $\mathrm{mg} / \mathrm{dL}$ & & $0.75 \pm 0.31(0.34-2.62)$ \\
\hline \multicolumn{3}{|l|}{ Concomitant medications } \\
\hline Opioids & $27(13.0)$ & \\
\hline Morphine & 2 & \\
\hline Oxycodone & 9 & \\
\hline Fentanyl & 7 & \\
\hline Tramadol & 1 & \\
\hline Others & 8 & \\
\hline NSAIDS & $43(20.7)$ & \\
\hline Neurotropin & $12(5.8)$ & \\
\hline Benzodiazepine & $44(21.2)$ & \\
\hline Tricyclic antidepressant & $22(10.6)$ & \\
\hline \multicolumn{3}{|l|}{ Combination therapies } \\
\hline Nerve block & $62(29.8)$ & \\
\hline Epiduroscopy & $24(11.5)$ & \\
\hline Phototherapy & $40(19.2)$ & \\
\hline \multicolumn{3}{|l|}{ Target diseases } \\
\hline Postherpetic neuralgia & $75(36.1)$ & \\
\hline $\begin{array}{l}\text { Cancer-related } \\
\text { neuropathic pain }\end{array}$ & $18(8.7)$ & \\
\hline $\begin{array}{l}\text { Failed back surgery } \\
\text { syndrome }\end{array}$ & $14(6.7)$ & \\
\hline Trigeminal neuralgia & $12(5.8)$ & \\
\hline $\begin{array}{l}\text { Complex regional pain } \\
\text { syndrome }\end{array}$ & $8(3.8)$ & \\
\hline
\end{tabular}

TABLE 1 - CONTINUED

Patient characteristics and extracted factors that may affect effectiveness or adverse effects associated with pregabalin for neuropathic pain $(n=208)$

\begin{tabular}{lcc}
\hline Characteristic & $\mathbf{n}(\%)^{*}$ & Mean \pm SD (range) \\
\hline Spine disease & $21(10.1)$ & \\
Spinal canal stenosis & $11(5.3)$ & \\
Osteoarthritis & $7(3.4)$ \\
Hernia & $3(1.4)$ \\
Diabetic peripheral & $3(1.4)$ \\
$\quad$ neuropathy & & \\
Others & $57(27.4)$ & \\
\hline
\end{tabular}

*Binary scales were: female $=0$ and male $=1$ for sex; $<60$ years of age $=0$ and $\geq 60$ years of age $=1$ for age; $<1.0 \mathrm{mg} / \mathrm{dL}(88.4 \mu \mathrm{mol} / \mathrm{L})=0$ and $\geq 1.0 \mathrm{mg} / \mathrm{dL}$ $(88.4 \mu \mathrm{mo} / \mathrm{L})=1$ for serum creatinine level; $<100 \mathrm{mg} /$ day $=0$ and $\geq 100 \mathrm{mg} /$ day $=1$ for initial dose $;<150 \mathrm{mg} /$ day $=0$ and $\geq 150 \mathrm{mg} /$ day $=1$ for maintenance dose; and absent $=0$ and present $=1$ for others. Ordinal scales were: $\leq 2$ weeks $=0$; $>2$ weeks but $\leq 1$ month $=1 ;>1$ month but $\leq 2$ months $=2$; and $>2$ months $=3$ for duration of therapy. ALT Alanine aminotransferase; AST Aspartate aminotransferase; NSAIDS Nonsteroidal anti-inflammatory drugs

based on interviews with the patients in daily clinical practice. The occurrence of an adverse event of grade $\geq 1$ according to the Common Terminology Criteria for Adverse Events version 4.0 was regarded as a positive event. Variables were extracted from the clinical records for regression analysis of factors related to the occurrence of adverse events associated with pregabalin administration. Predictive variables included sex, age, body mass index, dose and duration of pregabalin therapy, laboratory tests, concomitant medications, combination therapies and target disease. Target diseases were PHN, cancer-related NP, failed back surgery syndrome, trigeminal neuralgia, complex regional pain syndrome, spine disease (spinal canal stenosis, osteoarthritis, hernia), DPNP and others. Concomitant drug use was defined as the administration of another drug for $\geq 2$ weeks at the time of evaluation for adverse events. Body mass index and laboratory tests were extracted at the time of last evaluation. Binary scales were used for sex $($ female $=0 ;$ male $=1)$; age $(<60$ years $=0 ; \geq 60$ years $=1)$; serum creatinine level $(<1.0 \mathrm{mg} / \mathrm{dL}[88.4 \mu \mathrm{mol} / \mathrm{L}]=0 ; \geq 1.0 \mathrm{mg} / \mathrm{dL}[88.4 \mu \mathrm{mol} / \mathrm{L}]$ $=1)$; initial dose $(<100 \mathrm{mg} /$ day $=0 ; \geq 100 \mathrm{mg} /$ day $=1)$; maintenance dose $(<150 \mathrm{mg} /$ day $=0 ; \geq 150 \mathrm{mg} /$ day $=1)$; and other variables (no = 0 ; yes $=1$ ). Ordinal scales were $\leq 2$ weeks $=0 ;>2$ weeks but $\leq 1$ month $=1 ;>1$ month but $\leq 2$ months $=2 ;$ and $>2$ months $=3$ for duration of therapy. All potential predictive variables were screened for multicollinearity, which was defined as a correlation coefficient $>0.7$ between any two predictors. A lack of multicollinearity ensured the appropriate use of the multivariate regression model. Variables were further screened with the forward selection procedure, after which multivariate logistic regression analysis was performed using the selected variables. Threshold measures were examined using an ROC curve (16). All statistical analyses were performed using JMP version 9 (SAS Institute, USA) at a two-sided significance level of $\mathrm{P}<0.05$.

\section{RESULTS}

Adverse events were observed in 118 patients (56.7\%). Pregabalin was discontinued due to adverse events in 32 patients (15.4\%). These adverse events comprised somnolence in nine patients, dizziness in two, unsteadiness in 16, weight gain in two and edema in four (some patients experienced two or three adverse events). All patients showed full resolution of symptoms after discontinuation of pregabalin. Table 1 summarizes the clinical characteristics of the patients administered pregabalin, as well as the selected predictors related to adverse events of pregabalin. Predictive factors for adverse events were identified using logistic regression analysis. Predictive factors were: duration of therapy (OR 1.684 [95\% CI 1.179 to 2.406]; $\mathrm{P}=0.0042$ ) for somnolence; nonsteroidal anti-inflammatory drugs (NSAIDs) (OR 0.132 [95\% CI 0.030 to 0.578]; $\mathrm{P}=0.0072$ ), age (OR 3.137 [95\% CI 1.220 to 8.066 ]; $\mathrm{P}=0.0177)$ and maintenance dose (OR 
TABLE 2

Results of logistic regression analysis for variables extracted by forward selection

\begin{tabular}{|c|c|c|c|c|c|c|}
\hline Variable & Estimated value & SE & $\chi^{2}$ & $\mathbf{P}$ & OR & $95 \% \mathrm{Cl}$ \\
\hline \multicolumn{7}{|c|}{ Response $Y=$ somnolence (accuracy $=125 / 208$ ) } \\
\hline Duration of therapy & 0.521 & 0.182 & 8.21 & $0.0042^{*}$ & 1.684 & $1.179-2.406$ \\
\hline TCA & -0.811 & 0.669 & 1.47 & 0.2259 & 0.445 & $0.120-1.651$ \\
\hline Serum creatinine & 0.782 & 0.581 & 1.81 & 0.1781 & 2.186 & $0.700-6.826$ \\
\hline \multicolumn{7}{|c|}{ Response $Y=$ unsteadiness (accuracy = 159/208) } \\
\hline NSAIDs & -2.027 & 0.755 & 7.21 & $0.0072^{*}$ & 0.132 & $0.030-0.578$ \\
\hline Maintenance dose & -0.828 & 0.357 & 5.37 & $0.0205^{*}$ & 0.437 & $0.217-0.880$ \\
\hline \multicolumn{7}{|c|}{ Response $Y=$ body weight gain (accuracy $=164 / 208$ ) } \\
\hline Neurotropin & 1.473 & 0.914 & 2.6 & 0.1068 & 4.364 & $0.728-26.156$ \\
\hline Serum creatinine & 1.862 & 0.730 & 6.52 & $0.0107^{*}$ & 6.439 & $1.541-26.902$ \\
\hline \multicolumn{7}{|c|}{ Response $Y=$ edema (accuracy $=164 / 208$ ) } \\
\hline Neurotropin & 2.144 & 1.019 & 4.43 & $0.0353^{*}$ & 8.538 & $1.159-62.901$ \\
\hline
\end{tabular}

${ }^{*} P<0.05$. BUN Blood urea nitrogen; NSAIDs Nonsteroidal anti-inflammatory drugs; TCA Tricyclic antidepressant

0.437 [95\% CI 0.217 to 0.880]; P=0.0205) for unsteadiness; serum creatinine level (OR 6.439 [95\% CI 1.541 to 26.902]; P=0.0107) for weight gain; and neurotropin (OR 8.538 [95\% CI 1.159 to 62.901]; P=0.0353) and serum creatinine (OR 6.912 [95\% CI 1.118 to 42.726]; $\mathrm{P}=0.0375$ ) for edema. Accuracy refers to the ratio of patients whose expected value is equal to the observed value (Table 2). Using an ROC curve with a creatinine threshold $>0.83$, the highest sensitivity $(67 \%)$ and specificity (73\%) were obtained for the occurrence of weight gain (area under the curve $=0.68$ ); with a creatinine threshold $>1.02$, the highest sensitivity (63\%) and specificity (91\%) were obtained for the occurrence of edema (area under the curve $=0.78$ ).

\section{DISCUSSION}

Our findings indicate that predictive factors for the occurrence of adverse events were: duration of therapy for somnolence; use of NSAIDs, age and maintenance dose for unsteadiness; serum creatinine for weight gain; and use of neurotropin and serum creatinine for edema.

Duration of therapy was identified as a predictive factor for somnolence. This result showed that pregabalin does not induce any tolerance for somnolence. The only predictor Frame et al (17) identified for the time to first nonzero dizziness or drowsiness score due to pregabalin was the daily titrated dose. Thus, clinicians need to consider reducing the dose of pregabalin if patients report feeling very sleepy. Tricyclic antidepressants (TCAs) showed a low, but not significant, OR for somnolence; this finding may suggest the safety of the combined use of pregabalin and TCAs. The combination of pregabalin and TCAs may be associated with reduced somnolence.

No administration of NSAIDs and advanced age were identified as significant factors for unsteadiness. Unsteadiness occurred even with relatively low maintenance doses. These findings suggest the safety of the combined use of pregabalin and NSAIDs. Clinicians need to exercise caution when administering pregabalin to elderly patients, due to the risk of unsteadiness. Addition of NSAIDs to the regimen of an elderly patient on pregabalin may mitigate the risk of unsteadiness. On the other hand, NSAIDs are independently associated with significant adverse effects, particularly in elderly patients (eg, unheralded gastrointestinal bleeding); clinicians should, therefore, be alert to combined use of pregabalin and NSAIDs in elderly patients. The safety of the combination of the agents would require more detailed study. In addition, pregabalin shows a linear pharmacokinetic profile (18). However, unsteadiness did not occur in a dose-dependent manner. Clinicians should, therefore, be alert to initial unsteadiness when prescribing pregabalin.

Elevated serum creatinine level was identified as a predictive factor for weight gain. Pregabalin is eliminated primarily unchanged by renal excretion (19); therefore, accumulation of pregabalin due to delayed elimination through the kidney may cause weight gain. Stephen et al (20) identified dose-related weight gain due to pregabalin; our results support that finding. Clinicians should be cautious when prescribing pregabalin to patients with altered renal function.

Elevated serum creatinine level and combination use with neurotropin were identified as predictive factors for edema. Cumulative dosage of pregabalin due to delayed elimination through the kidneys may cause edema in addition to weight gain, reinforcing the need for clinicians to exercise care regarding renal function when prescribing pregabalin. Neurotropin, a nonprotein extract isolated from inflamed rabbit skin after inoculation with vaccinia virus, acts on the descending pain inhibitory system and has been widely used in Japan for the treatment of disorders associated with chronic pain (21-23). Edema due to neurotropin has been reported infrequently; thus, the possibility of edema arising in combination use of pregabalin and neurotropin needs to be considered.

In our study, dizziness was observed in $2.9 \%$ of patients. On the other hand, previous studies have concluded that dizziness in patients treated with pregabalin occurred in $17 \%$ to $46 \%(24,25)$. It may also be due to the difference in drug metabolism between Japanese and Caucasian patients, the difference in disease, or the low maintenance dose in the present study because the daily dose of our subjects was $152.2 \pm 96.4 \mathrm{mg}$ whereas the dose used in previous studies was $300 \mathrm{mg}$ to $600 \mathrm{mg}(24,25)$.

The present study had several limitations. First, the retrospective nature of the investigation may have decreased the reliability of the data collected. Second, the present study was performed at a single centre and involved a relatively small number of patients; therefore, the results should be confirmed in a further multicentre study.

\section{CONCLUSION}

We used a statistical approach to identify factors predicting adverse events associated with administration of pregabalin for NP. Our findings indicate that care is warranted regarding long duration of therapy for somnolence, advanced age rather than dose-dependent adverse events for unsteadiness, elevated serum creatinine level for weight gain, and elevated serum creatinine level and combination use of neurotropin for edema. Our study also demonstrated the safety of the combined use of pregabalin and NSAIDs. These findings should be considered preliminary and in need of further refinement and study. However, statistical identification of predictive factors should contribute to establish optimal protocols for pregabalin use.

DISCLOSURES: The authors have no conflicts of interest to declare. 


\section{REFERENCES}

1. Dworkin RH, Corbin AE, Young JP Jr, et al. Pregabalin for the treatment of postherpetic neuralgia: A randomized, placebocontrolled trial. Neurology 2003;60:1274-83.

2. Sabatowski R, Gálvez R, Cherry DA, et al. Pregabalin reduces pain and improves sleep and mood disturbances in patients with postherpetic neuralgia: Results of a randomised, placebo-controlled clinical trial. Pain 2004;109:26-35.

3. Stacey BR, Barrett JA, Whalen E, Phillips KF, Rowbotham MC. Pregabalin for postherpetic neuralgia: Placebo-controlled trial of fixed and flexible dosing regimens on allodynia and time to onset of pain relief. J Pain 2008;9:1006-17.

4. Barbarisi M, Pace MC, Passavanti MB, et al. Pregabalin and transcutaneous electrical nerve stimulation for postherpetic neuralgia treatment. Clin J Pain 2010;26:567-72.

5. Freynhagen R, Strojek K, Griesing T, Whalen E, Balkenohl M. Efficacy of pregabalin in neuropathic pain evaluated in a 12-week, randomised, double-blind, multicentre, placebo-controlled trial of flexible- and fixed-dose regimens. Pain 2005;115:254-63.

6. Zin CS, Nissen LM, O'Callaghan JP, Duffull SB, Smith MT, Moore BJ. A randomized, controlled trial of oxycodone versus placebo in patients with postherpetic neuralgia and painful diabetic neuropathy treated with pregabalin. J Pain 2010;11:462-71.

7. Moon DE, Lee DI, Lee SC, et al. Efficacy and tolerability of pregabalin using a flexible, optimized dose schedule in Korean patients with peripheral neuropathic pain: A 10-week, randomized, double-blind, placebo-controlled, multicenter study.

Clin Ther 2010;32:2370-85.

8. Guan Y, Ding X, Cheng Y, et al. Efficacy of pregabalin for peripheral neuropathic pain: Results of an 8-week, flexible-dose, double-blind, placebo-controlled study conducted in China. Clin Ther 2011;33:159-66.

9. Gilron I, Wajsbrot D, Therrien F, Lemay J. Pregabalin for peripheral neuropathic pain: A multicenter, enriched enrollment randomized withdrawal placebo-controlled trial. Clin J Pain 2011;27:185-93.

10. Lesser H, Sharma U, LaMoreaux L, Poole RM. Pregabalin relieves symptoms of painful diabetic neuropathy: A randomized controlled trial. Neurology 2004;63:2104-10.

11. Richter RW, Portenoy R, Sharma U, Lamoreaux L, Bockbrader H, Knapp LE. Relief of painful diabetic peripheral neuropathy with pregabalin: A randomized, placebo-controlled trial. J Pain 2005;6:253-60.

12. Tölle T, Freynhagen R, Versavel M, Trostmann U, Young JP Jr. Pregabalin for relief of neuropathic pain associated with diabetic neuropathy: A randomized, double-blind study. Eur J Pain 2008;12:203-13.
13. Satoh J, Yagihashi S, Baba M, et al. Efficacy and safety of pregabalin for treating neuropathic pain associated with diabetic peripheral neuropathy: A 14 week, randomized, double-blind, placebocontrolled trial. Diabet Med 2011;28:109-16.

14. Vondracek P, Oslejskova H, Kepak T, et al. Efficacy of pregabalin in neuropathic pain in paediatric oncological patients. Eur J Paediatr Neurol 2009;13:332-6.

15. Ogawa S, Satoh J, Arakawa A, Yoshiyama T, Suzuki M. Pregabalin treatment for peripheral neuropathic pain: A review of safety data from randomized controlled trials conducted in Japan and in the West. Drug Saf 2012;35:793-806.

16. Akobeng AK. Understanding diagnostic tests 3: Receiver operating characteristic curves. Acta Paediatr 2007;96:644-7.

17. Frame B, Miller R, Hutmacher MM. Joint modeling of dizziness, drowsiness, and dropout associated with pregabalin and placebo treatment of generalized anxiety disorder. J Pharmacokinet Pharmacodyn 2009;36:565-84.

18. Shneker BF, McAuley JW. Pregabalin: A new neuromodulator with broad therapeutic indications. Ann Pharmacother 2005;39:2029-37.

19. Bockbrader HN, Radulovic LL, Posvar EL, et al. Clinical pharmacokinetics of pregabalin in healthy volunteers. J Clin Pharmacol 2010;50:941-50.

20. Stephen LJ, Parker P, Kelly K, Wilson EA, Leach V, Brodie MJ. Adjunctive pregabalin for uncontrolled partial-onset seizures: Findings from a prospective audit. Acta Neurol Scand 2011;124:142-5.

21. Fukuda Y, Berry TL, Nelson M, et al. Stimulated neuronal expression of brain-derived neurotrophic factor by neurotropin. Mol Cell Neurosci 2010;45:226-33.

22. Kawashiri T, Egashira N, Watanabe H, et al. Prevention of oxaliplatin-induced mechanical allodynia and neurodegeneration by neurotropin in the rat model. Eur J Pain 2011;15:344-50.

23. Okazaki R, Namba H, Yoshida H, Okai H, Miura T, Kawamura M. The antiallodynic effect of neurotropin is mediated via activation of descending pain inhibitory systems in rats with spinal nerve ligation. Anesth Analg 2008;107:1064-9.

24. Moore RA, Straube S, Wiffen PJ, Derry S, McQuay HJ. Pregabalin for acute and chronic pain in adults. Cochrane Database Syst Rev 2009;(3):CD007076

25. Kwan P, Brodie MJ, Kälviäinen R, Yurkewicz L, Weaver J, Knapp LE. Efficacy and safety of pregabalin versus lamotrigine in patients with newly diagnosed partial seizures: A phase 3, doubleblind, randomised, parallel-group trial. Lancet Neurol 2011;10:881-90. 


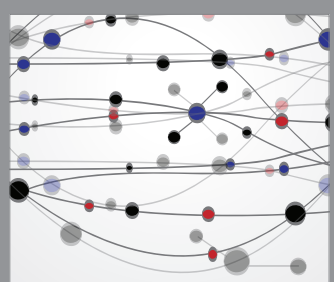

The Scientific World Journal
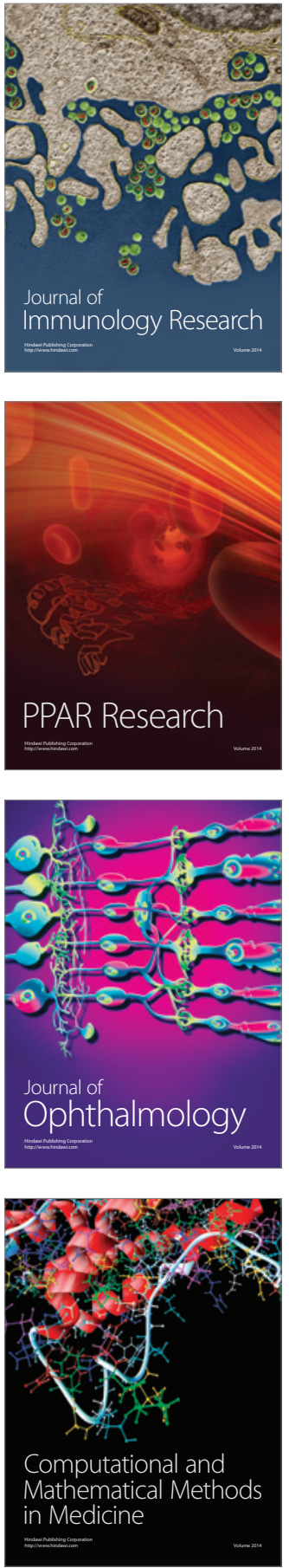

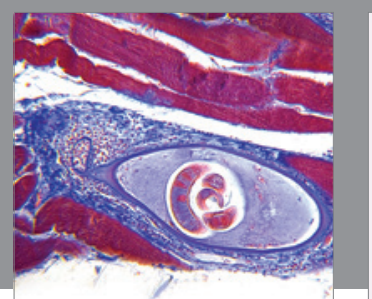

Gastroenterology Research and Practice

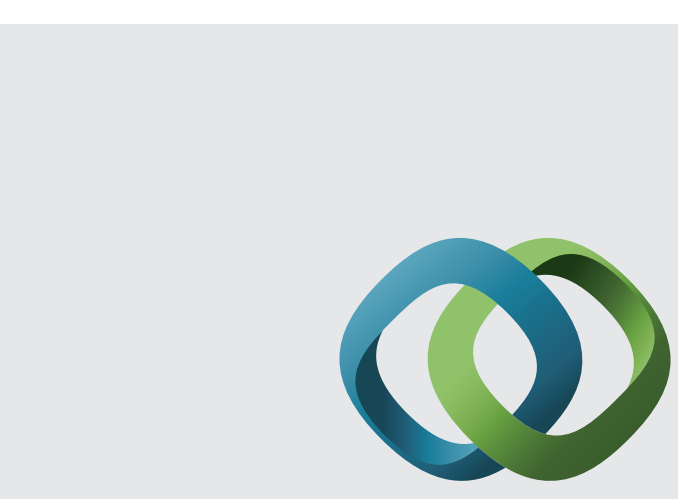

\section{Hindawi}

Submit your manuscripts at

http://www.hindawi.com
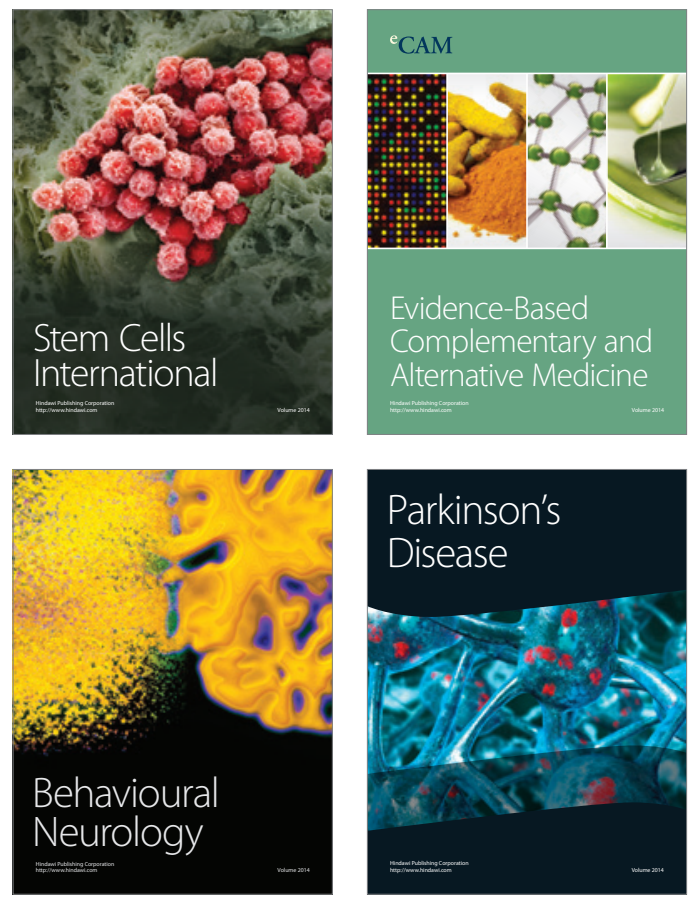
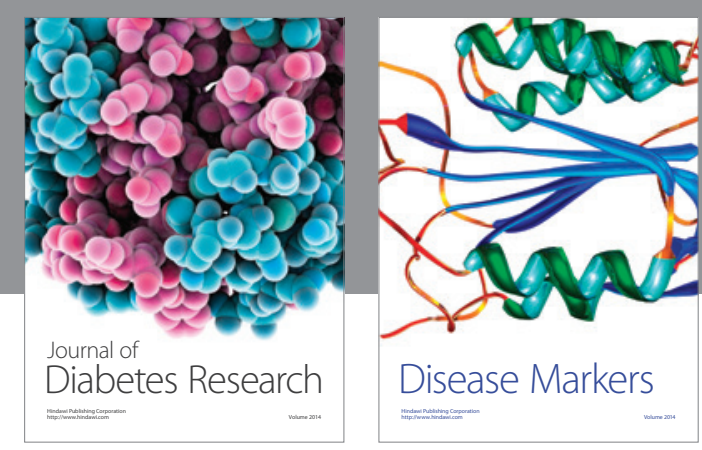

Disease Markers
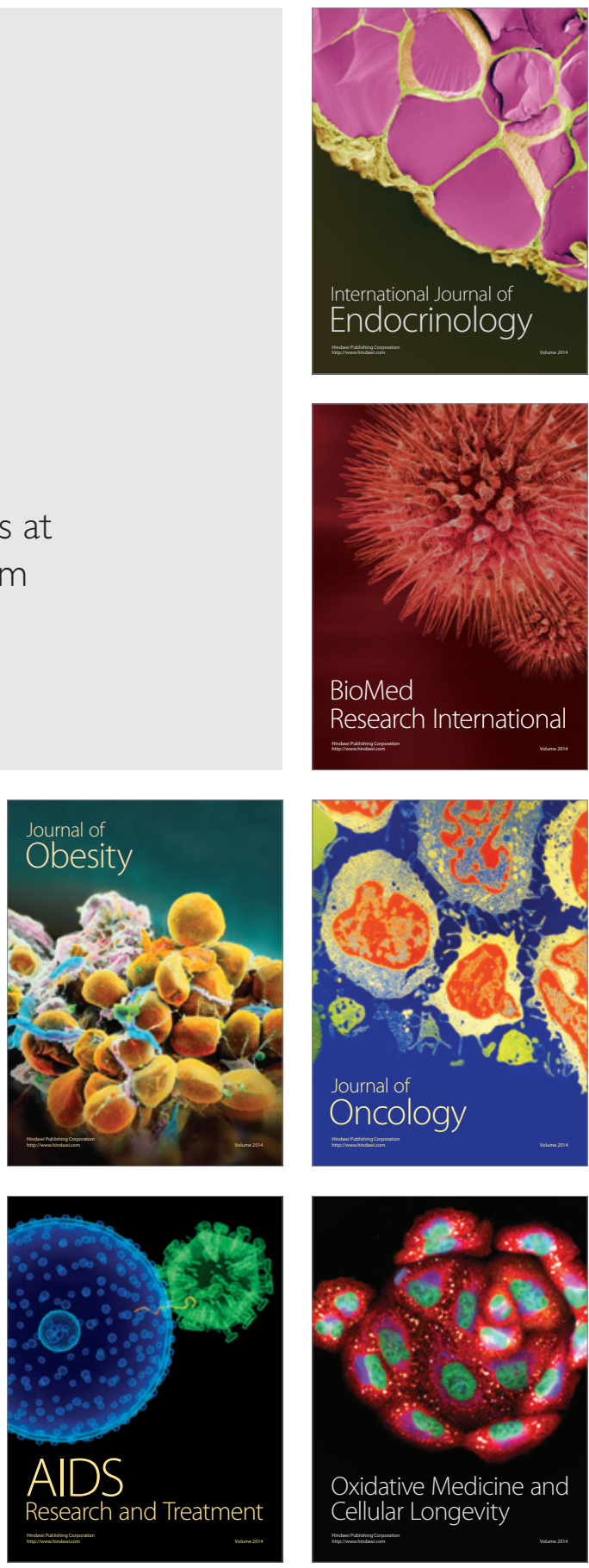